\title{
Partial left pericardial defect with herniation of the left atrial appendage
}

\author{
C. PER NOT, J-C. H O E F F E L, M. HEN R Y, R. F R I S C H,
} a nd B. B R A UER

Departments of Cardiology and Radiology, University Hospital Jeanne d'Arc, 54-Dommartin-les-Toul, Franc

A case is reported of herniation of the left atrial appendage through a partial pericardial defect, probably congenital. The diagnosis was suggested by the history of chest pain and bulging of the middle segment of the left heart border on the plain chest film, without other signs. Angiography revealed a dilated left atrial appendage. An artificial left pneumothorax confirmed the presence of a pleuropericardial defect. The surgical procedure included excision of the appendage and closure of the defect.

We report a case of partial congenital pericardial defect with herniation of the left atrial appendage. A tentative diagnosis was made from a history of chest pain and a pulsating, left hilar shadow on fluoroscopy. The diagnosis was confirmed by angiography and left pneumothorax and was verified at surgery.

The diagnosis of partial or total congenital pericardial defect is seldom established before surgery although this malformation is usually easily recognized if its possible existence is considered. Colombus reported the first case in 1559 but Baillie (1793) gave the first complete description.

A pericardial defect is rarely total or localized entirely to the left side. Usually a partial left pericardial defect exists, causing, because of its location, herniation of the left appendage. This explains the clinical and radiological signs. Dahl (1937) first emphasized the value of pneumothorax in the diagnosis of congenital pericardial defect. Ellis, Leeds, and Himmelstein (1959) described the main radiological features and Dimond, Kittle, and Voth (1960) the cineangiographic patterns.

\section{CASE REPORT}

G.M., a 17-year-old male student, was admitted because of constrictive chest pain. There was no typical irradiation but for several months the pain appeared after effort. The first painful crisis with syncope and intense pallor occurred during a game of football.

Fluoroscopy revealed a pseudomitral pattern of the left heart border. The lack of other signs ruled out mitral stenosis, atrial septal defect, pulmonary val: vular stenosis, and primary pulmonary hypertension?

A diagnosis of dilatation of the left atrial append age was suggested but a mediastinal tumour coulc not be excluded. After this first crisis the boy suffereck from other less severe chest pains, always related to effort. He was admitted to the University Hospitas for further investigation.

Physical examination revealed a well-develope young man, $56.6 \mathrm{~kg}$ in weight and $166 \mathrm{~cm}$ in height On auscultation a physiological double second sound was heard and was confirmed by phonocardiographyo A chest radiograph and fluoroscopy showed ax localized, pulsating bulge of the left atrial appendage The electrocardiogram was normal: axis $+60^{\circ}, \mathrm{PR}^{2}$. interval a little short $(0 \cdot 12 \mathrm{sec})$, ventricular de 8 polarization normal with, during repolarization, slighe upper deviation of the ST segment with $T$ biphasiog in V2 and V3, and bifidity of $\mathrm{T}$ in V4.

Right heart catheterization revealed a slight in $\frac{\overrightarrow{ }}{2}$ crease of pressure in the right atrium but no other. abnormality. The results were: right atrium $+8 /-\mathrm{W}$ mean $=7 \mathrm{mmHg}$; right ventricle $+30 /-5$ mean $=10$ $\mathrm{mmHg}$; pulmonary artery $+30 /-8$ mean $=14 \mathrm{mmHg}$ ? pulmonary capillaries $+10 /-6$ mean $=+8 \quad m m H g N$ Oxymetry was normal. Retrograde left ventricularo catheterization confirmed normal pressure in the aorta and the left ventricle.

Selective angiography of the pulmonary arteryes showed that it was normal, but when the left atrium was opacified a champagne cork shaped density re $\frac{0}{0}$ lated to the dilated left appendage could be seen The diagnosis was confirmed by means of a diagnostio? pneumothorax following the injection of $400 \mathrm{ml}$ of $\mathbb{Q}$ air into the left pleural cavity. Chest radiographs wereo taken in the frontal, right anterior oblique, and left lateral decubitus positions with a horizontal beam. 
These views outlined the pericardium with air from the pneumothorax (Figure). Lateral prone films outlined the left appendage with a thin rim of air around it.

As the diagnosis of left pericardial defect with left appendage herniation was established, surgery was recommended because pain suggested a strangulation of the left appendage. In fact the patient was readmitted within one week because of severe precordial pain with intense dyspnoea and hypertension. On 12 December 1970 a left thoracotomy through the fourth intercostal space was performed. Immediately on opening the pleural cavity the left appendage could be seen pulsating into the pleural space anterior to the left pulmonary hilum. There was a localized defect of the left pericardium at the level of the left inferior pulmonary vein. The left atrial appendage herniated into the pleural cavity. There were no adhesions between the heart and the pericardium. Resection of the appendage and suture of the pericardial defect were performed. Care was taken not to constrict the heart.

Postoperatively the patient had a pleuropericardial reaction without fever but with moderate pain in the left chest and a gross pleuropericardial friction rub. The ECG pattern suggested a diffuse subepicardial ischaemia. The sedimentation rate was $34 \mathrm{~mm}$ in one hour. Corticosteroids and antibiotics were given. The pleural murmur disappeared after 48 hours but drug therapy was continued. The ECG remained abnormal. When the patient was discharged on 10 January 1971 his clinical condition was good but ECG changes were still present. The bulge of the left hilum was still visible on the chest film, although the defect had been repaired.

\section{DISCUSSION}

FREQUENCY OF PERICARDIAL DEFECTS According to Saint Pierre and Froment (1970), who collected 153 cases of pericardial defect, the percentage of each variety was as follows:

$\begin{array}{lr}\text { Total absence of pericardium } & 9 \% \\ \text { Left-sided defect } & \\ \text { Partial } & 35 \% \\ \text { Total } & 35 \% \\ \text { Right-sided defect } & \\ \text { Partial } & 4 \% \\ \text { Total } & 0 \% \\ \text { Diaphragmatic pericardial aplasia } & 17 \% .\end{array}$

From the literature between 1945 and 1971, we have collected 43 cases of left pericardial defect localized to the area of the hilus and diagnosed during the life of the patient and added our own

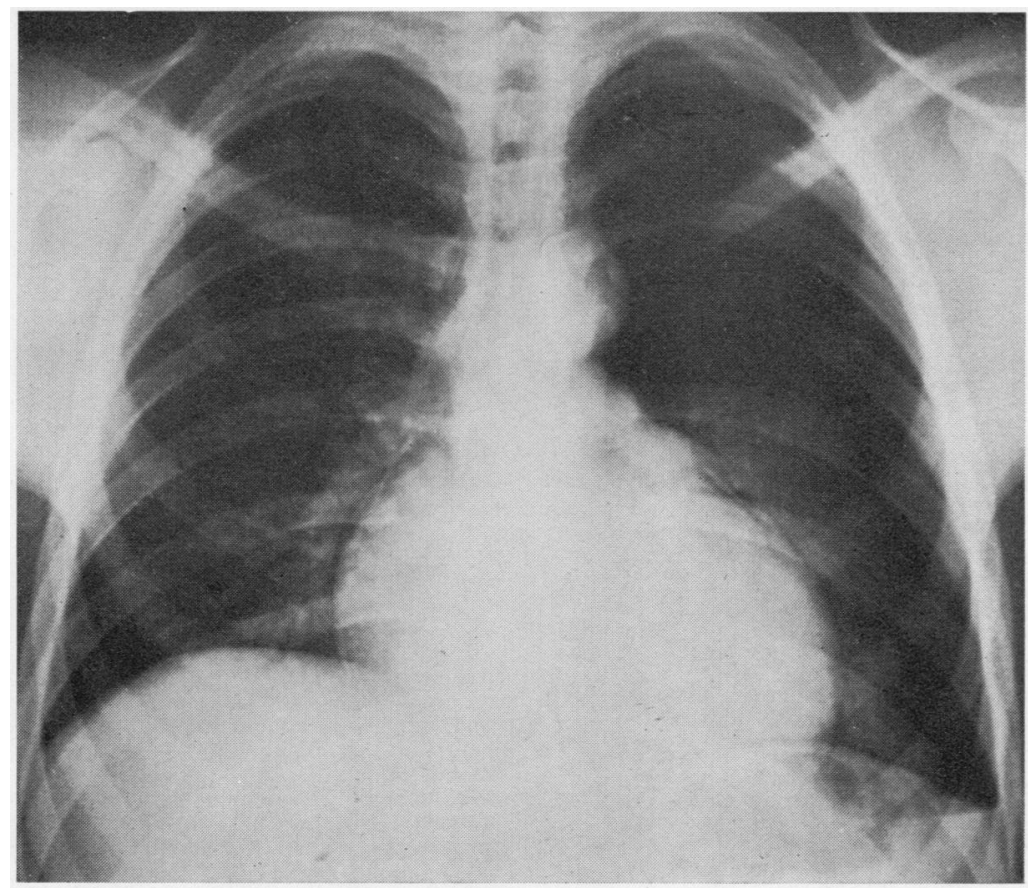

FIGURE. Chest radiograph after induction of left pneumothorax. Intrapericardial air can be seen on both sides of the cardiac shadow. 
case. Twenty-five out of 44 patients were male. In 21 of the 44 patients the disease was discovered between the ages of 10 and 30 years.

EMBRYOLOGY Many theories attempt to explain a partial left pericardial defect which is the consequence of lack of separation of the primary coelomic cavity. The most credible theory is that pericardial defects result from premature atrophy of the left duct of Cuvier, resulting in a compromised vascular circulation of the left pleuropericardial membrane which would eventually become the left pericardium. Support for this theory is the frequency of left-sided defects while rightsided lesions are rare. The frequency of associated anomalies, usually cardiovascular or pulmonary, is about $30 \% \quad(37 \%$, Saint Pierre and Froment, 1970; $30 \%$, Neimann, Pernot, Prevot, and Marchal, 1967).

Among our 44 cases (including our own case) were seven bronchogenic cysts, three cases of patent ductus arteriosus, three ventricular septa 6 defects with pulmonary stenosis and another with aortic stenosis, one tetralogy of Fallot, one corv triatriatum, one congenital mitral insufficiency,, and one isolated pulmonary stenosis. The fre quency of associated abnormalities was $38.6 \%$ (17 out of 44 cases).

SYMPтомS We studied only those cases in which $\overrightarrow{\vec{\omega}}$ the pericardial defect was isolated (Table). Among? the 27 cases 16 were asymptomatic; 8 presented with chest pain, sometimes with irradiation to the left arm, and dyspnoea. Three of these eight casesiv had occasional syncopal attacks, two had dysp noea but no pain, and one had small haemoptyses. According to most authors, chest pain is due tos mediastinal adhesions, torsion of the great vessels by lack of complete stability of the heart, or to lesions of the coronary arteries (the left in Hering Wilson, and Ball's case (1960) from pressure by the fibrous rim of the pericardial defect).

T A B L E

PARTIAL PERICARDIAL DEFECT WITH HERNIATION OF THE LEFT APPENDAGE (44 CASES)

\begin{tabular}{|c|c|c|c|c|c|c|c|c|}
\hline & & & & & Clinical Signs & Angiography & Pneumothorax & Thoracotomy \\
\hline \multicolumn{5}{|c|}{ Without an associated congenital malformation ( 27 cases): } & & & & \\
\hline Fry $(1953) \cdots$ & $\cdots$ & . & $\cdots$ & $\cdots$ & 0 & 0 & 0 & + \\
\hline $\begin{array}{l}\text { Hering et al. }(1960) \text { case } 1 \\
\text { case } 2\end{array}$ & $\cdots$ & $\cdots$ & . & $\cdots$ & + & + & $\begin{array}{l}0 \\
0\end{array}$ & + \\
\hline \multirow{3}{*}{\multicolumn{3}{|c|}{ 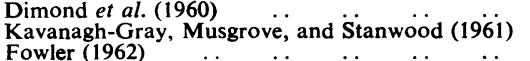 }} & $\begin{array}{l}\cdots \\
\cdots\end{array}$ & $\begin{array}{l}\cdots \\
\ldots\end{array}$ & 0 & + & 0 & + \\
\hline & & & . & . & 0 & + & 0 & + \\
\hline & & $\ldots$ & $\ldots$ & . & + & + & + & + \\
\hline \multirow{2}{*}{\multicolumn{2}{|c|}{$\begin{array}{l}\text { Duffie, Moss, and Maloney (1962) } \\
\text { Tucker, Miller, and Jacoby (1963) case } i\end{array}$}} & $\ldots$ & $\ldots$ & . & + & + & 0 & + \\
\hline & & $\ldots$ & $\ldots$ & $\ldots$ & + & + & 0 & + \\
\hline \multirow{9}{*}{ 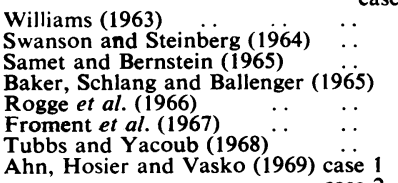 } & & $\ldots$ & $\ldots$ & . & 0 & + & 0 & + \\
\hline & $\ldots$ & $\ldots$ & $\ldots$ & $\ldots$ & + & + & 0 & + \\
\hline & $\ldots$ & $\ldots$ & $\ldots$ & $\ldots$ & + & + & 0 & + \\
\hline & $\ldots$ & $\ldots$ & $\ldots$ & . & + & + & 0 & 0 \\
\hline & $\ldots$ & $\ldots$ & $\ldots$ & $\ldots$ & $\mathbf{0}$ & + & + & + \\
\hline & $\ldots$ & $\ldots$ & $\ldots$ & $\ldots$ & $\mathbf{0}$ & + & + & 0 \\
\hline & $\ldots$ & $\ldots$ & $\ldots$ & $\ldots$ & 0 & + & 0 & 0 \\
\hline & . & $\ldots$ & . & . & + & + & 0 & + \\
\hline & $\cdots$ & . & . & . & 0 & + & + & 0 \\
\hline case 2 & . & . & . & . & $\mathbf{0}$ & + & 0 & 0 \\
\hline \multirow{3}{*}{$\begin{array}{l}\text { Ahlberg, Bartley and Paulin (1969) } \\
\text { Nasser et al. (1970a and b) case } 1 \\
\end{array}$} & $\ldots$ & . & . & . & $\mathbf{0}$ & $\mathbf{0}$ & 0 & + \\
\hline & $\cdots$ & $\cdots$ & . & . & $\mathbf{0}$ & + & + & $\mathbf{0}$ \\
\hline & $\cdots$ & . & $\cdots$ & $\cdots$ & + & + & 0 & $\mathbf{0}$ \\
\hline \multirow{6}{*}{$\begin{array}{lll}\text { Deutsch } \text { et al. }(1970) & \ldots & \ldots \\
\begin{array}{l}\text { Greenberg } \text { et al. }(1970) \\
\text { Pernot (present case) }\end{array} & \ldots & \ldots \\
\text { Schulte, Bircks and Wilke (1969) } & \ldots \\
\text { Nogrady and Nemec (1970) case } 1 \\
\text { case } 2\end{array}$} & $\cdots$ & $\cdots$ & $\cdots$ & . & 0 & + & 0 & 0 \\
\hline & $\cdots$ & $\cdots$ & . & . & + & 0 & 0 & + \\
\hline & . & $\cdots$ & $\cdots$ & $\cdots$ & + & + & + & + \\
\hline & $\cdots$ & $\cdots$ & $\cdots$ & $\cdots$ & 0 & 0 & 0 & $\overline{0}$ \\
\hline & $\cdots$ & $\cdots$ & $\cdots$ & $\cdots$ & $\begin{array}{l}\mathbf{0} \\
0\end{array}$ & + & $\begin{array}{l}0 \\
0\end{array}$ & 0 \\
\hline & & & & & & & & 0 \\
\hline \multirow{3}{*}{\multicolumn{4}{|c|}{$\begin{array}{l}\text { With an associated congenital malformation (17 cases): } \\
\text { Rusby and Holmes Sellors (1945) (bronchogenic cyst) } \\
\text { Coury, Monod and Tournier (1956) (bronchogenic cyst) } \\
\text { Jones (1955) } 1 \text { (bronchogenic cyst) } \quad \text {. . . . } \quad . .\end{array}$}} & & & & & \\
\hline & & & & . & + & 0 & + & + \\
\hline & & & & $\therefore$ & $\begin{array}{l}\mathbf{0} \\
\mathbf{0}\end{array}$ & $\begin{array}{l}0 \\
+\end{array}$ & $\mathbf{0}$ & $\begin{array}{c}0 \\
+\end{array}$ \\
\hline 2 (bronchogenic cyst) & $\ddot{\cdots}$ & $\begin{array}{l}\cdots \\
\cdots\end{array}$ & $\begin{array}{l}\cdots \\
\cdots\end{array}$ & $\ddot{\cdots}$ & 0 & 0 & 0 & 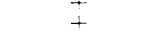 \\
\hline 3 (bronchogenic cyst) & . & . & . & . & 0 & 0 & $\mathbf{0}$ & + \\
\hline \multirow{2}{*}{\multicolumn{4}{|c|}{ Chang and Leigh (1961) (patent ductus arteriosus) $\quad$. }} & $\ldots$ & 0 & $\mathbf{0}$ & $\mathbf{0}$ & + \\
\hline \multirow{2}{*}{\multicolumn{4}{|c|}{$\begin{array}{l}\text { Bor and Kafka (1961) case } 1 \text { (V.S.D.) } \ldots \text { arteriosus) } \\
\text { case } 2 \text { (patent ductus arter. }\end{array}$}} & $\ldots$ & + & o & 0 & + \\
\hline \multirow{5}{*}{\multicolumn{5}{|c|}{$\begin{array}{l}\text { Hipona and Grummy (1964) (Fallot) } \\
\text { Mukerjee (1964) (bronchogenic cyst) } \\
\text { Broadbent } \text { et al. (1966) case 1 (patent ductus arteriosis) } \\
\text { case 2 (V.S.D. with pulmonary stenosis) }\end{array}$}} & + & $\mathbf{0}$ & $\mathbf{0}$ & + \\
\hline & & & & & + & $\mathbf{0}$ & $\mathbf{0}$ & + \\
\hline & & & & & + & 0 & 0 & + \\
\hline & & & & & No mention & No mention & No mention & 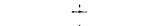 \\
\hline & & & & & No mention & No mention & No mention & + \\
\hline \multirow{3}{*}{\multicolumn{5}{|c|}{$\begin{array}{l}\text { Ahn, Hosier, and Vasko (1969) (cor triatriatum) } \\
\text { Bayard, Gaudeau and Vernant (1970) (mitral insufficiency) } \\
\text { Schulte et al. (1969) case } 1 \text { (bronchogenic cyst) } \\
\text { case } 2 \text { (aortic stenosis with coarctation and }\end{array}$}} & $\begin{array}{l}+ \\
+\end{array}$ & $\begin{array}{l}+ \\
+\end{array}$ & $\begin{array}{l}\mathbf{0} \\
\mathbf{0}\end{array}$ & + \\
\hline & & & & & No mention & No mention & No mention & + \\
\hline & & & & & & & No mention & + \\
\hline \multicolumn{5}{|c|}{ Iljin and Skotnicki (1970) (pulmonary stenosis) } & No mention & 0 & 0 & + \\
\hline
\end{tabular}


If syncope is present, the condition may endanger life because of possible herniation of the heart through the pericardium, and incarceration in this position may occur. Saint Pierre and Froment (1970) collected from the literature five deaths due to herniation of the left ventricle. No deaths due to herniation of the left atrium or its appendage were reported by Rogge, Mishkin, and Genovese (1966).

PHYSICAL SIGNS Among 27 cases of isolated partial defect we noted that 16 were without physical signs, while in 11 cases there was a systolic murmur localized to the second or third left intercostal space. Only in one case was a systolic murmur associated with a diastolic murmur (Samet and Bernstein, 1965). In this case the diagnosis was made only on angiography but no mention of any surgical procedure was made.

No electrocardiographic changes are noticed unless there are associated cardiac anomalies.

RADIOLOGICAL SIGNS In 19 of the 27 cases chest radiographs showed a prominence of the left hilar shadow, referred to as the pulmonary artery on 17 occasions. In our case it must be emphasized that the prominence was localized to the left atrial appendage while the main pulmonary artery was located well above.

In eight cases, a left hilar opacity was noted but no firm diagnosis was made. In eight cases fluoroscopy revealed excessive pulsation of the localized bulging of the left border with or without expansion.

CATHETERIZATION AND ANGIOGRAPHY Right catheterization was performed in 16 out of 27 cases studied. Intracardiac and pulmonary artery pressures were always normal during rest.

In his two cases Nasser (1966) noted an elevation of the pulmonary artery and left ventricular end-diastolic pressures during mild exercise which consisted of raising and lowering the left lower extremity for four minutes while in the recum. bent position. He believes that a portion of the heart could herniate and temporarily incarcerate during exercise through the abnormal pericardial foramen, resulting in elevation of pulmonary artery and left ventricular end-diastolic pressures.

Angiography was performed in 22 cases. In 19 cases it proved that the bulging of the middle segment of the left heart border was due to a large left appendage.

According to some authors, herniation of the left appendage appears only during ventricular systole. In the case of Samet and Bernstein (1965) angiography was normal; a transseptal catheterization of the left atrium was done and the herniated appendage was opacified.

A left diagnostic pneumothorax was performed in 6 out of 27 cases and always induced a pneumopericardium which proved the abnormal pleuropericardial communication.

According to some authors pneumopericardium may not appear if pericardial adhesions prevent the entry of air into the pericardial space or if there is no pleural defect opposite the pericardial one. Our opinion is that one cannot be sure that a pericardial defect exists if no artificial pneumothorax has been done.

DIAGNOSIS On plain film, a diagnosis of atrial dilatation, mitral stenosis, and causes of enlargement of the pulmonary artery must be considered, such as idiopathic dilatation of the pulmonary artery, hypertension from any cause, pulmonary valvular stenosis, and large left-to-right shunts (especially atrial septal defect). These malformations induce either bulging of the upper part (and not the lower half) of the middle segment of the left heart border or bulging of the entire middle segment ; moreover clinical signs are informative. Mediastinal opacities (lymph nodes or tumours) can usually be excluded with the aid of mediastinal tomography but differentiation is not always easy and some patients diagnosed as having tumours are operated upon.

Rare anomalies such as pulmonary arteriovenous aneurysm or ventricular aneurysm can easily be eliminated, if necessary by means of angiography. Finally, bulging of the middle segment of the left heart border secondary to simple rotation of the infundibulum and pulmonary artery (Froment, Loire, Dalloz, and Age, 1967) can be ruled out by angiography and, if necessary, by means of an artificial pneumothorax.

A difficult problem, resolved only by artificial pneumothorax, is the diagnosis of aneurysm of the left appendage without pericardial defect. Froment et al. (1967) collected four such cases from the literature, and Saint-Florent, Duboys, Neveux, and Mathey (1967) also published one case. Artificial pneumothorax is the most reliable method of diagnosis of a pericardial defect in a patient with a prominent pulsating left middle segment, and no abnormal cardiac sign.

SURGICAL TREATMENT Seventeen of 27 cases without associated lesions were operated upon. The surgical procedures included pericardioplasty on six occasions (three with left appendage excision and three divisions of adhesions-one with exci- 
sion of the appendage). In three cases extension of the defect was carried out. Among the nine patients with associated cardiac defects the pericardial foramen was closed on two occasions. In most cases the left appendage was very dilated but never aneurysmal.

\section{REFERENCES}

Ahlberg, N. E., Bartley, O., and Paulin, S. (1969). Roentgenologic diagnosis of congenital pericardial defect. Acta radiol., 8, 42.

Ahn, A. C., Hosier, D. M., and Vasko, J. S. (1969). Congenital pericardial defect with herniation of the left atrial appendage. Ann. thorac. Surg., 7, 369.

Baillie, M. (1793). On the want of a pericardium in the human body. Trans. Soc. Improve med. and chir. Knowl., 1,91 .

Baker, W. P., Schlang, H. A., and Ballenger, F. P. (1965). Congenital partial absence of the pericardium. Amer. J. Cardiol., 16, 133.

Bayard, J. P., Gaudeau, S., and Vernant, P. (1970). Absence congenitale partielle du pericarde. Auricule gauche ectasique. Insuffisance mitrale majeure. Coeur, 1, 621.

Bor, I., and Kafka, V. (1961). Aplasia of the pericardium. J. Cardiovasc. Surg., 2, 389.

Broadbent, J. C., Callahan, J. A., Kincaid, O. W., and Ellis, F. H. (1966). Congenital deficiency of the pericardium. Dis. Chest, 50, 237.

Chang, C. H. J., and Leigh, T. F. (1961). Congenital partial defect of the pericardium associated with herniation of the left atrial appendage. Amer. J. Roentgenol., 86, 517.

Columbus, R. (1559). De re anatomica. 15, 265 (Venice)

Coury, C., Monod, O., and Tournier, J. (1956). Coexistence chez un enfant de deux kystes bronchogéniques du médiastin et d'une incoalescence partielle du pericarde. J. frans. Méd. Chir. thor., 10, 271.

Dahl, E. (1937), Et Tilfelle av medfoldt pericarddefekt diagnostisert after angelaw ventresiding pneumothorax. Med. Rev (Bergen), 54, 312.

Deutsch, V., Yahini, J. H., Shem-Tov, A., and Neufeld, H. N. (1970). Congenital pericardial defect. Brit. J. Radiol., 43, 67.

Dimond, E. G., Kittle, C. F., and Voth, D. W. (1960). Extreme hypertrophy of the left atrial appendage. The case of the giant dog ear. Amer J. Cardiol., 5, 122

Duffie, E. R., Moss, A. J., and Maloney, J. V. (1962). Congenital pericardial defects with herniation of the heart into the pleural space. Pediatrics, 30, 746.

Ellis, K., Leeds, N. E., and Himmelstein, A. (1959). Congenital deficiencies in the parietal pericardium. Amer. $J$. Roentgenol., 82, 125.

Fowler, N. O. (1962). Congenital defect of the pericardium: its resemblance to pulmonary artery enlargement. Circulation, 26, 114.

Froment, R., Loire, R., Dalloz, C., and Age, C. (1967). "Hernie Congénitale" de l'auricule gauche avec ou sans déhiscence péricardique. A propos d'un case avec malposition infundibulo-pulmonaire associée. Arch. Mal. Coeur., 69, 1476.

Fry, W. (1953). Herniation of the left auricule. Amer.J. Surg., 86, 736.
Glover, L. B., Barcia, A., and Reeves, T. J. (1969). Con genital absence of the pericarduim. A review of the literature with demonstration of a previously unreporte fluoroscopic finding. Amer. J. Roentgenol., 106, 542.

Greenberg, B. H., Suros, J., Nunn, S. L., and McGoon D.C. (1970). Partial pericardial defect with constrictive pericarditis. Chest, 57, 383.

Hering, A. C., Wilson, J. S., and Ball, R. E. jr. (1960) Congenital deficiency of the pericardium. J. thorac: cardiovasc. Surg., 40, 49.

Hipona, F. A., and Grummy, A. B. (1964). Congenita. pericardial defect associated with tetralogy of Fallot Herniation of normal lung into the pericardial cavity Circulation, 29, 132.

Iljin, W., and Skotnicki, S. (1970). Congenital defects of̂ pericardium. Kardiol. pol., 13, 93.

Jones, P. (1955). Developmental defects in the lungs. Thorax $10,205$.

Kavanagh-Gray, D., Musgrove, E., and Stanwood, D. (1961). Congenital pericardial defects. Reports of a case. New Engl.J. Med., 265, 692.

Mukerjee, S. (1964). Congenital partial left pericardial defect̄ with a bronchogenic cyst. Thorax, 19, 176.

Nasser, W. K. (1966). Congenital absence of the left peri- $\overrightarrow{0}$ cardium. Circulation, 34, 100.

, Helmen, C., Tavel, M. E., and Feigenbaum, H. (1970a)? Hemodynamic determinations in congenital absence of the left pericardium. Amer. J. Cardiol., 25, 119.

- , and Fisch, C. (1970b). Congenitalo absence of the left pericardium. Clinical electrocardiographic radiographic, hemodynamic and angio-ه graphic findings in six cases. Circulation, 41, 469.

Neimann, N., Pernot, C., Prevot, J., and Marchal, C. (1967). $\overrightarrow{\overrightarrow{0}}$ Aplasie du péricarde associée à une hernie diaphragmatique et à un hamartome hépatique intrathoracique. Rev. Pédiat., 3, 35

Nogrady, B., and Nemec, J. (1970). Partial congenital defect: in childhood. Report of four cases. J. Canad. Ass. Radiol., 21, 116.

Rogge, J. D., Mishkin, M. E., and Genovese, P. D. (1966). ֻٕ Congenital partial pericardial defect with herniation of 0 the left atrial appendage. Ann. intern. Med., 64, 137.

Rusby, N. L., and Holmes Sellors, T. (1945). Congenital deficiency of the pericardium associated with a bronchogenic cyst. Brit. J. Surg., 32, 357.

Saint-Florent, G. de, Duboys, Y., Neveux, J. Y., and 윽 Mathey, J. (1967). Anévrysme congénital de l'auricule. Ann. Chir. thorac. cardiovasc., 6, 110.

Saint Pierre, A., and Froment, R. (1970). Absences totales et partielles du péricarde. Arch. Mal. Coeur., 63, 638 .

Samet, P., and Bernstein, W. H. (1965). Herniation of the left atrial appendage. Amer. J. Cardiol., 16, 454.

Schulte, H. D., Bircks, W., and Wilke, K. H. (1969). స Angeborene Defekte des Herzbeutels. Thoraxchirurgie, 17, 271.

Swanson, G. E., and Steinberg, I. (1964). Roentgen features of the atrial appendages. Amer. J. Roentgenol., 91, 311. \&

Tubbs, O. S., and Yacoub, M. H. (1968). Congenital pericardial defect. Thorax, 23, 598.

Tucker, D. H., Miller, D. E., and Jacoby, W. J. (1963). Congenital partial absence of the pericardium with herniation of the left atrial appendage. Amer. J. Med., 35,560 .

Williams, W. G. (1963). Dilatation of the left atrial appendage. Brit. Heart J., 25, 637. 